\title{
The influence of stratospheric vortex displacements and splits on surface climate
}

Article

Published Version

Mitchell, D. M., Gray, L. J., Anstey, J., Baldwin, M. P. and Charlton-Perez, A. (2013) The influence of stratospheric vortex displacements and splits on surface climate. Journal of Climate, 26 (8). pp. 2668-2682. ISSN 1520-0442 doi: https://doi.org/10.1175/JCLI-D-12-00030.1 Available at https://centaur.reading.ac.uk/34207/

It is advisable to refer to the publisher's version if you intend to cite from the work. See Guidance on citing.

Published version at: http://dx.doi.org/10.1175/JCLI-D-12-00030.1

To link to this article DOI: http://dx.doi.org/10.1175/JCLI-D-12-00030.1

Publisher: American Meteorological Society

All outputs in CentAUR are protected by Intellectual Property Rights law, including copyright law. Copyright and IPR is retained by the creators or other copyright holders. Terms and conditions for use of this material are defined in the End User Agreement.

www.reading.ac.uk/centaur 
Central Archive at the University of Reading

Reading's research outputs online 


\title{
The Influence of Stratospheric Vortex Displacements and Splits on Surface Climate
}

\author{
DANiel M. Mitchell, Lesley J. GRAy, AND JAmes ANSTEy \\ National Centre for Atmospheric Science, University of Oxford, Oxford, United Kingdom \\ MARK P. BALDWIN \\ Northwest Research Associates, Seattle, Washington \\ Andrew J. Charlton-Perez \\ Department of Meteorology, University of Reading, Reading, United Kingdom
}

(Manuscript received 4 January 2012, in final form 14 September 2012)

\begin{abstract}
A strong link exists between stratospheric variability and anomalous weather patterns at the earth's surface. Specifically, during extreme variability of the Arctic polar vortex termed a "weak vortex event," anomalies can descend from the upper stratosphere to the surface on time scales of weeks. Subsequently the outbreak of cold-air events have been noted in high northern latitudes, as well as a quadrupole pattern in surface temperature over the Atlantic and western European sectors, but it is currently not understood why certain events descend to the surface while others do not. This study compares a new classification technique of weak vortex events, based on the distribution of potential vorticity, with that of an existing technique and demonstrates that the subdivision of such events into vortex displacements and vortex splits has important implications for tropospheric weather patterns on weekly to monthly time scales. Using reanalysis data it is found that vortex splitting events are correlated with surface weather and lead to positive temperature anomalies over eastern North America of more than $1.5 \mathrm{~K}$, and negative anomalies over Eurasia of up to $-3 \mathrm{~K}$. Associated with this is an increase in high-latitude blocking in both the Atlantic and Pacific sectors and a decrease in European blocking. The corresponding signals are weaker during displacement events, although ultimately they are shown to be related to cold-air outbreaks over North America. Because of the importance of stratospheretroposphere coupling for seasonal climate predictability, identifying the type of stratospheric variability in order to capture the correct surface response will be necessary.
\end{abstract}

\section{Introduction}

Polar stratospheric variability is largely dominated by vertically propagating Rossby waves of tropospheric origin (Andrews et al. 1987). The resulting stratospheric anomalies can in turn descend and influence surface climate; although the mechanism for this coupling has received much attention over the past decade, no clear consensus has emerged. Among the leading theories are wave-mean flow interactions (Christiansen 2001; Wittman et al. 2007) and wave reflections at the stratopause (Perlwitz and Harnik 2003). The coupling time

Corresponding author address: Daniel Mitchell, Atmospheric, Oceanic and Planetary Physics, University of Oxford, Oxford OX1 3PU, United Kingdom.

E-mail: mitchell@atm.ox.ac.uk scales are, however, more accurately constrained, with northern annular mode (NAM) anomalies from weak and strong vortex events descending from the midstratosphere to the surface on time scales of weeks (Baldwin and Dunkerton 2001). The resulting influence at the surface can cause midlatitude storms to become more intense, storm tracks to shift latitudinally, and the frequency of high-latitude blocking events to change (Thompson and Wallace 2001). Traditionally, weak vortex events have been defined as either a "major sudden stratospheric warming," where a substantial fraction of the vortex air mass is rigorously mixed into the background flow, or a "minor sudden stratospheric warming," where the vortex air mass is disturbed but not to the same extent. Both types of event have often been defined using diagnostics based on the zonal mean (Charlton and Polvani 2007, hereafter CP07) or annular mode (Thompson 
and Wallace 1998). However, recent research has shown increased understanding of these events when vortex centric diagnostics are used, such as $2 \mathrm{D}$ vortex moments (Waugh 1997; Waugh and Randel 1999; Mitchell et al. 2011a,b), which inherently take into account the zonally asymmetric nature of weak vortex events.

During weak vortex events the vortex can either be displaced off the pole (vortex displacement events) or split into two daughter vortices (vortex splitting events), and these are known to be predominantly associated with vertically propagating Rossby waves of wavenumber 1 and 2, respectively (Andrews et al. 1987). The structure and evolution of the vortex during these types of events also differ greatly (Matthewman et al. 2009; Mitchell et al. 2011a) and may play an important role for understanding surface climate (Nakagawa and Yamazaki 2006).

We know from Hoskins et al. (1985) and Ambaum and Hoskins (2002) that a positive potential vorticity (PV) anomaly in the stratosphere will result in an elevated tropopause and vice versa. Indeed a point change in stratospheric $\mathrm{PV}, \Delta q$, can be linked to changes in the tropopause pressure, $\Delta p_{\text {trop }}$, via the following relationship:

$$
\Delta q \approx-q(1+\mathrm{Bu}) \frac{\Delta p_{\text {trop }}}{p_{\text {trop }}},
$$

where $\mathrm{Bu}$ is the Burger number. We also note that

$$
q=\frac{\left(f+\nabla_{H}^{2} \psi\right)}{\sigma},
$$

where $f$ is the Coriolis parameter, $\nabla_{H}^{2} \psi$ is the relative vorticity, $H$ refers to the horizontal component, and $\sigma$ is a stratification-related mass density.

In the context of this study, high positive PV over the pole (i.e., the polar vortex) moving equatorward where there is lower ambient PV will result in a large positive $\mathrm{PV}$ anomaly in this region, which as a fractional change will be larger than the negative PV anomaly over the pole (i.e., where the vortex used to be). This will be reflected in either a larger positive anomaly in $\nabla_{H}^{2} \psi$ or a bigger reduction in $\sigma$, or probably both (Ambaum and Hoskins 2002). This movement of PV will broadly result in the following two features:

1) a sinking of the tropopause over the pole where the vortex used to be, and

2) an elevation of the tropopause at lower latitudes to where the vortex has been shifted.

As the PV anomaly is larger at lower latitudes, the change in tropopause height will also be greater in magnitude. However, the climatological tropopause height will be higher than in the polar region and hence communication to the surface may well be harder in this sense. Importantly, point 1 above will lead to similarities in surface influences for both splits and displacements, but point 2 will lead to differences due to the vortex residing at different latitudes and longitudes depending on the event type.

Wilcox et al. (2012) showed, using a blended thermal and dynamical tropopause definition, that significant variations in tropopause height were observed along the longitude plain as well as that of the latitude. While they did not explicitly deal with the polar vortex, long-term trends in the tropopause height may well be associated with extreme vortex events. If the tropopause is elevated in a certain region and depressed in another, then the change in thermal expansion and contraction of the troposphere may well influence surface climate.

With the possibility that weak vortex events will increase under climate change (Bell et al. 2009), as well as the possibility that the ratio of displacement to splitting events may also increase (Mitchell et al. 2012a,b), the need to understand surface influences for each type of event separately is becoming ever more crucial.

\section{Methods}

\section{a. Classification of event type}

We use the 40-yr European Centre for Medium-Range Weather Forecasts (ECMWF) Re-Analysis (ERA-40) dataset over the period December 1958-April 2002. The data are available at 6 -h time intervals and have 23 vertical pressure levels that range between 1000 and $1 \mathrm{hPa}$, with 12 of these levels representing the stratosphere. Note that the analysis was also undertaken using $\mathrm{Na}-$ tional Centers for Environmental Prediction (NCEP)National Center for Atmospheric Research (NCAR) data, and similar results were obtained.

Using ERA-40, we calculate elliptical diagnostics (Waugh 1997; Waugh and Randel 1999) of the Arctic polar vortex to obtain time series of the vortex area, aspect ratio, and centroid latitude on the $850-\mathrm{K}$ isentropic surface $(\sim 10 \mathrm{hPa})$ (Mitchell et al. 2011a). The results were insensitive to the choice of level between 650 and $1050 \mathrm{~K}(\sim 30-5 \mathrm{hPa})$. This calculation involves identifying the PV contour that represents the vortex edge $\bar{q}$ as the sharpest potential vorticity gradient in an equivalent latitude frame (Nash et al. 1996) and then applying PV weighting functions (2D vortex moments) inside the vortex region, defined in Cartesian coordinates as

$$
\mu_{a b}=\iint_{S}[q(x, y)-\bar{q}] x^{a} y^{b} d x d y
$$


where $q$ is the potential vorticity, $a$ is the moment order in the $x$ direction, $b$ is the moment order in the $y$ direction (both $a$ and $b$ are nonnegative integers), and $S$ is the surface of the vortex (Mitchell et al. 2011a).

To change from Cartesian to polar coordinate systems we use a polar stereographic projection (Waugh 1997),

$$
x=\frac{\cos (\lambda) \cos (\phi)}{1+\sin (\phi)}, \quad y=\frac{\sin (\lambda) \cos (\phi)}{1+\sin (\phi)},
$$

where $\lambda$ is the longitude and $\phi$ is the latitude.

Equation (3) allows for the calculation of time series of the following:

1) The vortex area $A$, which is given by the zeroth-order moment, $a=0$ and $b=0$ (i.e., $A \approx \mu_{00}$ ).

2) The vortex centroid latitude $\phi_{\text {cent }}$, which is given by the first-order moment and is defined in Cartesian coordinates as $(\bar{x}, \bar{y}) \approx\left(\mu_{01}, \mu_{10}\right)$. Transforming back to polar coordinates then yields

$$
\phi_{\text {cent }}=\tan ^{-1}\left(\frac{\bar{x}}{\bar{y}}\right)
$$

3) The vortex aspect ratio $r$, which is given by the second-order moment such that

$$
r=\left\{\frac{\left(J_{20}+J_{02}\right)+\left[4 J_{11}^{2}+\left(J_{20}-J_{02}\right)^{2}\right]^{1 / 2}}{\left(J_{20}+J_{02}\right)-\left[4 J_{11}^{2}+\left(J_{20}-J_{02}\right)^{2}\right]^{1 / 2}}\right\}^{1 / 2},
$$

where $J$ denotes a transformation of Eq. (3) relative to the centroid of the vortex [see Matthewman et al. (2009) for more details].

Deseasonalized time series of $A, \phi_{\text {cent }}$, and $r$ were then run through a hierarchical clustering algorithm (Wilks 1995), which was able to correctly identify days in which the vortex was displaced, split, or stable, following the exact methodology of Hannachi et al. (2011) (the reader is referred to this study for technical details regarding the clustering algorithm). To add confidence to the definition, we officially define an event as either a split or displacement if the vortex remains in this state for at least five consecutive days. ${ }^{1}$ If the vortex state changes between split and displaced (i.e., does not return to the stable state) within this 5-day window, a mixed event is defined. A list of these events is given in Table 1, along with a comparison of weak vortex events defined in CP07.

\footnotetext{
${ }^{1}$ Applying persistence time scales of between 5 and 10 days does not alter the conclusions of this study.
}

Note that although we use the clustering algorithm to be consistent with Hannachi et al. (2011), similar dates can be achieved by using a simple threshold method in that splits are defined when the vortex aspect ratio is notably elliptical, and displacements when the centroid latitude is notably equatorward, adding confidence that the clustering algorithm is reliable in this case.

\section{b. Calculating the NAM}

The NAM (known as the Arctic oscillation at the surface) is the leading mode of wintertime variability in the Northern Hemisphere circulation (Thompson and Wallace 1998; Baldwin 2001). Here, we calculate the NAM as the leading empirical orthogonal function (EOF) of daily wintertime (November-April) geopotential anomalies poleward of $20^{\circ} \mathrm{N}$. The anomalies are calculated by subtracting the seasonal cycle, which has been smoothed with a 90-day low-pass filter. The daily NAM anomalies are then determined by projecting daily geopotential anomalies onto the leading EOF patterns. Finally, the NAM is normalized at each level so that the entire time series has unit variance. For this NAM definition we use the zonal-mean geopotential following Baldwin and Thompson (2009).

\section{c. Calculating blocking}

The blocking index is derived from daily-mean $500-\mathrm{hPa}$ geopotential height $Z_{500}$ according to the method of Tibaldi and Molteni (1990) as generalized to vary in both latitude and longitude by Scherrer et al. (2006). At each horizontal grid point with latitude $\phi$ and longitude $\lambda$, the equatorward meridional gradient of $Z_{500}$ is estimated as $\Delta_{\text {eqw }}=\left[Z_{500}(\lambda, \phi)-Z_{500}(\lambda, \phi-\Delta \phi)\right] / \Delta \phi$, where $\Delta \phi=15^{\circ}$ as in Scherrer et al. (2006). The poleward gradient is similarly defined as $\Delta_{\text {plw }}=\left[Z_{500}(\lambda, \phi+\right.$ $\left.\Delta \phi)-Z_{500}(\lambda, \phi)\right] / \Delta \phi$. An "instantaneous blocking" (IB) event is defined to occur when the following two conditions are fulfilled: 1) $\Delta_{\text {eqw }}>0$, indicating reversal of the climatological gradient of $Z_{500}$ with easterlies equatorward of $\phi$, and 2) $\Delta_{\text {plw }}<-10 \mathrm{~m}\left({ }^{\circ} \text { lat }\right)^{-1}$, indicating strong westerlies poleward of $\phi$. The IB index $b$ is defined to be 1 when these two conditions are satisfied, and 0 otherwise. The blocking frequency in events per day is simply the time mean of $b$.

\section{d. Statistics}

We use Student's $t$ tests and Monte Carlo resampling methods to assess statistical significance throughout this study. The null hypothesis of the Student's $t$ test is that the means of the datasets are not significantly different from zero. The validity of the test is also assessed by testing for Gaussianity of the data. 
TABLE 1. A summary table of weak vortex event onset dates from this study (column 2) compared with dates calculated in CP07 (column 5). Events are either classed as a displacement (D), a split (S), or a mix of both (M). The two studies are broadly said to be comparable if the onset dates are within a month of each other. Here $\Delta T_{10}$ reports the mean area-weighted $50^{\circ}-90^{\circ} \mathrm{N}$ cap temperature anomaly at $10 \mathrm{hPa}$ for 5 days on either side of the central warming date.

\begin{tabular}{|c|c|c|c|c|c|c|}
\hline No. & Event onset & Event type & $\Delta T_{10}(\mathrm{~K})$ & CP07 onset & CP07 type & $\Delta T_{10}(\mathrm{~K})$ \\
\hline 1 & 11 Mar 1959 & $\mathrm{D}$ & 4.1 & - & - & - \\
\hline 2 & 24 Dec 1959 & $\mathrm{~S}$ & 3.2 & 15 Jan 1960 & $\mathrm{D}$ & 5.9 \\
\hline 3 & 18 Dec 1960 & $\mathrm{~S}$ & 12.7 & - & - & - \\
\hline 4 & 8 Mar 1961 & $\mathrm{D}$ & 7.9 & - & - & - \\
\hline 5 & 2 Feb 1962 & $\mathrm{~S}$ & 2.1 & - & - & - \\
\hline 6 & 9 Mar 1962 & S & -2.1 & - & - & - \\
\hline 7 & 22 Jan 1963 & $\mathrm{~S}$ & 7.0 & 28 Jan 1963 & $\mathrm{~S}$ & 10.5 \\
\hline 8 & 10 Mar 1964 & $\mathrm{D}$ & 9.1 & - & - & - \\
\hline 9 & 14 Dec 1965 & $\mathrm{D}$ & 3.9 & 16 Dec 1965 & $\mathrm{D}$ & 6.7 \\
\hline 10 & - & - & - & 24 Feb 1966 & $\mathrm{~S}$ & 3.1 \\
\hline 11 & 2 Jan 1968 & $\mathrm{~S}$ & 14.4 & 7 Jan 1968 & $\mathrm{~S}$ & 12.0 \\
\hline 12 & - & - & - & 28 Nov 1968 & $\mathrm{D}$ & 5.3 \\
\hline 13 & - & - & - & 13 Mar 1969 & $\mathrm{D}$ & 4.3 \\
\hline 14 & - & - & - & 1 Jan 1970 & $\mathrm{~S}$ & 6.8 \\
\hline 15 & 16 Jan 1971 & $\mathrm{~S}$ & 11.4 & 18 Jan 1971 & S & 9.6 \\
\hline 16 & - & - & - & 19 Mar 1971 & $\mathrm{~S}$ & -2.9 \\
\hline 17 & 14 Feb 1972 & $\mathrm{~S}$ & 4.1 & - & - & - \\
\hline 18 & - & - & - & 31 Jan 1973 & $\mathrm{~S}$ & 6.6 \\
\hline 19 & 12 Mar 1974 & $\mathrm{D}$ & 4.3 & - & - & - \\
\hline 20 & 20 Jan 1975 & $\mathrm{~S}$ & 6.9 & - & - & - \\
\hline 21 & 15 Mar 1975 & $\mathrm{D}$ & 6.6 & - & - & - \\
\hline 22 & 28 Mar 1976 & $S$ & 6.3 & - & - & - \\
\hline 23 & - & - & - & 9 Jan 1977 & $S$ & 9.1 \\
\hline 24 & 19 Jan 1978 & $S$ & 1.4 & - & - & - \\
\hline 26 & 18 Feb 1979 & $\mathrm{~S}$ & 2.4 & 22 Feb 1979 & $\mathrm{~S}$ & 3.7 \\
\hline 27 & 15 Feb 1980 & $\mathrm{~S}$ & 2.7 & 29 Feb 1980 & $\mathrm{D}$ & 11.5 \\
\hline 28 & 16 Mar 1980 & $\mathrm{D}$ & 5.1 & 29 Feb 1980 & $\mathrm{D}$ & 11.5 \\
\hline 29 & - & - & - & 4 Dec 1981 & $\mathrm{D}$ & 0.1 \\
\hline 20 & 21 Jan 1982 & $S$ & 9.6 & - & - & - \\
\hline 30 & 22 Feb 1983 & $\mathrm{D}$ & 8.9 & - & - & - \\
\hline 31 & 26 Feb 1984 & $\mathrm{D}$ & 12.1 & 24 Feb 1984 & $\mathrm{D}$ & 11.1 \\
\hline 32 & 25 Dec 1984 & $\mathrm{~S}$ & 2.2 & 1 Jan 1985 & $\mathrm{~S}$ & 13.0 \\
\hline 33 & 3 Jan 1986 & S & -4.9 & - & - & - \\
\hline 34 & 13 Mar 1986 & $\mathrm{D}$ & 5.0 & - & - & - \\
\hline 35 & 18 Jan 1987 & $\mathrm{D}$ & 10.1 & 23 Jan 1987 & $\mathrm{D}$ & 10.2 \\
\hline 36 & 1 Dec 1987 & M & 7.6 & 7 Dec 1987 & $\mathrm{~S}$ & 14.1 \\
\hline 37 & 10 Mar 1988 & $\mathrm{D}$ & 11.7 & 14 Mar 1988 & $\mathrm{~S}$ & 11.7 \\
\hline 38 & 17 Feb 1989 & $\mathrm{D}$ & 14.7 & 21 Feb 1989 & $\mathrm{~S}$ & 12.8 \\
\hline 39 & 6 Feb 1990 & $\mathrm{D}$ & 6.1 & - & - & - \\
\hline 40 & 12 Jan 1992 & $\mathrm{D}$ & 12.8 & - & - & - \\
\hline 41 & 20 Mar 1992 & $\mathrm{D}$ & 6.5 & - & - & - \\
\hline 42 & 10 Jan 1995 & $\mathrm{~S}$ & 6.0 & - & - & - \\
\hline 43 & 13 Jan 1998 & $\mathrm{~S}$ & 2.4 & - & - & - \\
\hline 44 & 19 Feb 1998 & $\mathrm{D}$ & 5.6 & - & - & - \\
\hline 45 & 10 Dec 1998 & M & 10.7 & 15 Dec 1998 & $\mathrm{D}$ & 12.7 \\
\hline 46 & 27 Feb 1999 & $\mathrm{D}$ & 13.2 & 26 Feb 1999 & $\mathrm{~S}$ & 11.0 \\
\hline 47 & - & - & - & 20 Mar 2000 & $\mathrm{D}$ & 5.3 \\
\hline 48 & 3 Feb 2001 & $\mathrm{D}$ & 7.5 & 11 Feb 2001 & $\mathrm{D}$ & 6.3 \\
\hline 49 & 28 Dec 2001 & M & 14.9 & 30 Dec 2001 & $\mathrm{D}$ & 12.9 \\
\hline
\end{tabular}

The Monte Carlo method assesses significance by comparing the probability density function (PDF) of the average NAM during 18 randomly averaged samples with those specifically of splitting and displacement events, resampled $10^{5}$ times. Here a sample is defined as a random period of 45 consecutive days during any winter in the dataset. Note that 18 random events were used here because it is close to the composite of splitting events (18) and displacement events (19) determined during the classification stage. In reality the shape of the PDF 
does not vary greatly if 19 samples are used. The result is also not sensitive to the number of resampling iterations.

\section{Comparison with $\mathrm{CP07}$}

In this study, we distinguish between splitting and displacement vortex events using a clustering algorithm of the $850-\mathrm{K}(\sim 10 \mathrm{hPa})$ vortex area, aspect ratio, and centroid latitude (Mitchell et al. 2011a; Hannachi et al. 2011) to define 19 displacement events and 18 splitting events (see section 2). Our method is completely distinct from that of $\mathrm{CP} 07$, who class an event as disturbed when the zonal mean zonal wind (ZMZW) at $60^{\circ} \mathrm{N}$ and $10 \mathrm{hPa}$ reverses, and then proceed to class a split vortex when two vortices with a circulation ratio of 2:1 or higher are present (all other events are automatically defined as displacements). Table 1 gives a comparison between dates defined using our method (column 2) and those defined in CP07 (column 5). The average cap $\left(50^{\circ}-90^{\circ} \mathrm{N}\right)$ temperature anomaly at $10 \mathrm{hPa}$ for 5 days on either side of the event onset is also included to give a measure of event magnitude.

First, it is noted from Table 1 that our method identifies an expanded sample size of events relative to CP07. While many of the event dates are similar between the two studies, we note that the extra events included in this study are of high magnitude and seem to be as extreme as the previously identified events. Figure 1 shows the cap temperature anomaly at $10 \mathrm{hPa}$ for all events in Table 1 where our method defined an event, but CP07 did not (shown in blue), and all events in Table 1 where CP07 defined an event, but we did not (shown in red). The thick lines give composites of these events and on average our events are higher in magnitude than those of $\mathrm{CP} 07$, although we note that the differences are not statistically significant. It should be noted that two events using our definition actually have a colder-than-average polar cap temperature (Fig. 1, solid black lines), and these occur simply because the vortex is particularly disturbed after the peak in polar cap temperature; in one case this eventually leads to another large polar cap temperature anomaly.

A further interesting disparity between the two sets of dates is the inclusion of six new events during the 1990s. While traditionally thought of as a less dynamically active period than normal, this does not mean that extreme events were unable to occur. In particular the event on 12 January 1992 (event 40 in Table 1) was one of the largest on record in terms of cap temperature anomaly, reaching $12.8 \mathrm{~K}$. Considering this event more closely, Fig. 2 shows the evolution of the $850-\mathrm{K}(\sim 10 \mathrm{hPa})$ Northern Hemisphere PV fields at 2-day intervals following the onset. For reference a composite of PV during January is given in the top left panel. When contrasted

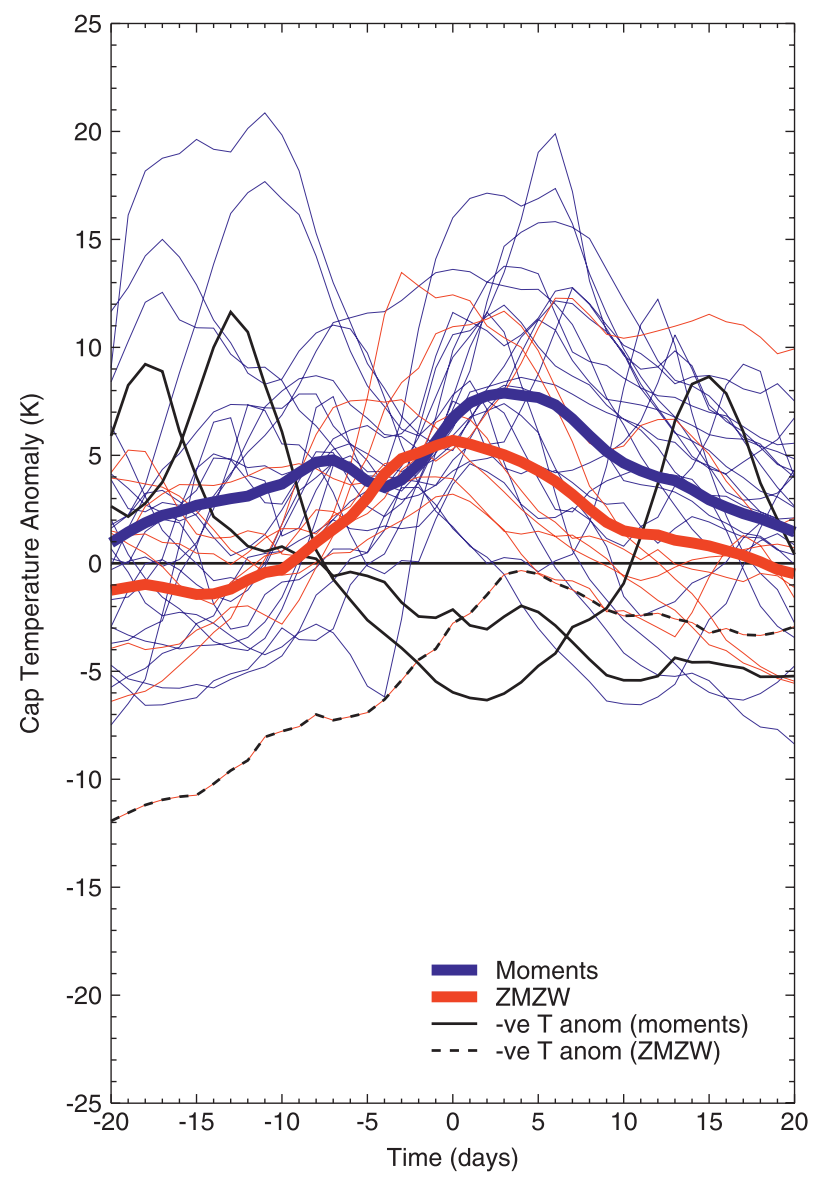

FIG. 1. Composites of the area-weighted $50^{\circ}-90^{\circ} \mathrm{N}$ cap temperature anomalies at $10 \mathrm{hPa}$ for (blue) the events that are defined in this study but missed in $\mathrm{CP} 07$ and (red) the events that are defined in $\mathrm{CP} 07$ but missed in this study. Thick lines show the average of all events. Thin lines show individual events. Black lines show events where the average cap temperature 5 days on either side of the central date is negative for (solid) the moment method and (dashed) the CP07 method.

with the composite, it is clear that the polar vortex during this particular event is highly displaced from the pole. Throughout the 8 days studied here the classic comma shape of the vortex can be observed, with a large filament of PV rotating out of the main vortex mass and being mixed into the background flow in a period of irreversible wave breaking. Large displacements such as this are particularly important as they represent a shift in spatial location of high-magnitude stratospheric PV, which may influence the tropopause and hence tropospheric circulation (Ambaum and Hoskins 2002). This particular result suggests that extreme vortex interactions over the 1990s may well be more abundant than previously thought.

Finally we compare the event type between our study and CP07. Figure 3 shows the event type as a function of month and year for (top) our study and (bottom) CP07. 
Jan Composite

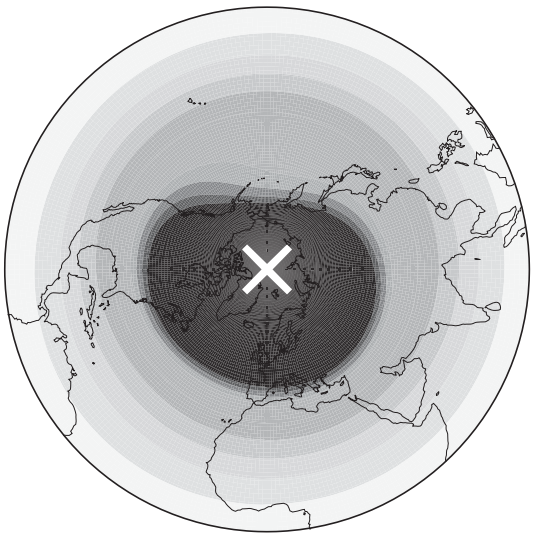

Onset +4 days

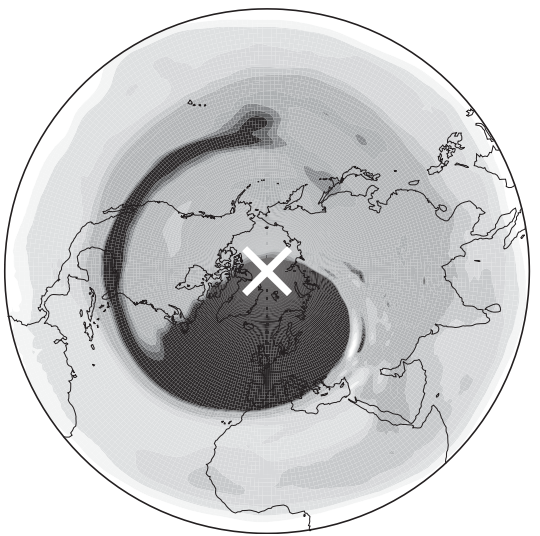

Onset

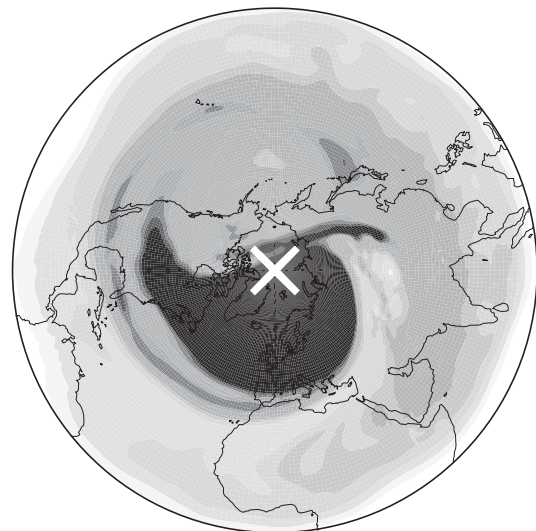

Onset +6 days

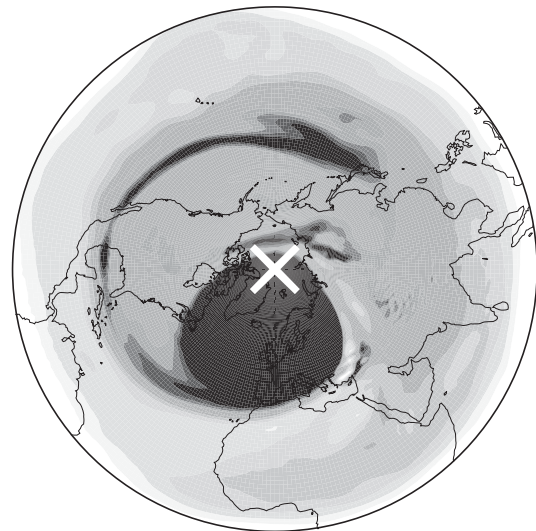

Onset +2 days

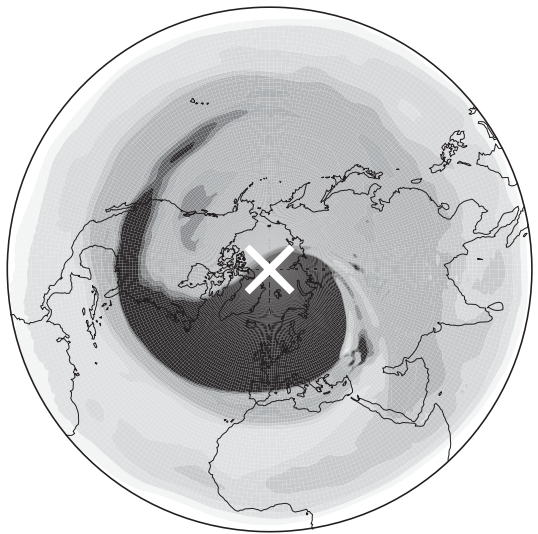

Onset +8 days

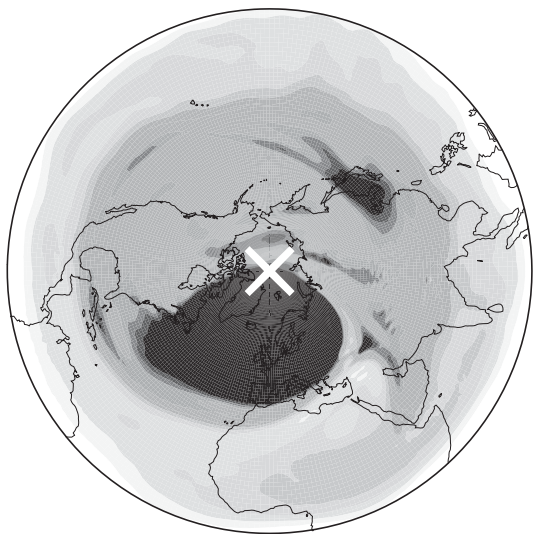

FIG. 2. Northern Hemisphere (NH) PV fields on the $850 \mathrm{~K}(\sim 10 \mathrm{hPa})$ surface for the event that began on 12 Jan 1992 . Top left shows the climatological January PV on the same surface.

We can see that in our study the majority of displacement events occur in February and March, whereas the majority of splits occur in December and January. In contrast, the events from $\mathrm{CP} 07$ seem to be more evenly distributed throughout the year, although as in our definition there is a tendency for splits to be more concentrated in January.

To summarize we note the following advantages and disadvantages of using the method developed here compared with CP07:

\section{Advantages:}

1) Our method uses a specifically developed vortex centric criterion in defining an event, and therefore takes into account the zonal asymmetry of the vortex evolution, whereas CP07 uses a method based on zonal symmetry.

2) Taking measurements at a single point, as in $\mathrm{CP} 07$ (i.e., at $60^{\circ} \mathrm{N}$ and $10 \mathrm{hPa}$ ) means that events are often missed that can occur elsewhere (e.g., $65^{\circ} \mathrm{N}$ and $7 \mathrm{hPa}$ ). Our method makes use of full longitude-latitude fields, although we note that as in $\mathrm{CP} 07$ it does not have a vertical dependence.

3) Using our definition often captures high-magnitude "minor" warmings, which can be more dynamically significant than "major" warmings defined in CP07. This allows for a higher sample size and therefore better statistics.

4) Our method explicitly defines splits and displacements, whereas $\mathrm{CP} 07$ only defines splits and infers that all other events where the $\mathrm{ZMZW}$ at $60^{\circ} \mathrm{N}$ and $10 \mathrm{hPa}$ is less than zero are displacements.

Disadvantages:

1) The use of zonal-mean wind in $\mathrm{CP} 07$ means that multimodel comparisons can be made with little effort. On the other hand, few models output PV, as needed for our method, so more effort is required in first calculating this quantity.

2) Our method depends on either a markedly elliptical vortex to define splits or extreme equatorward shifts 
(a)

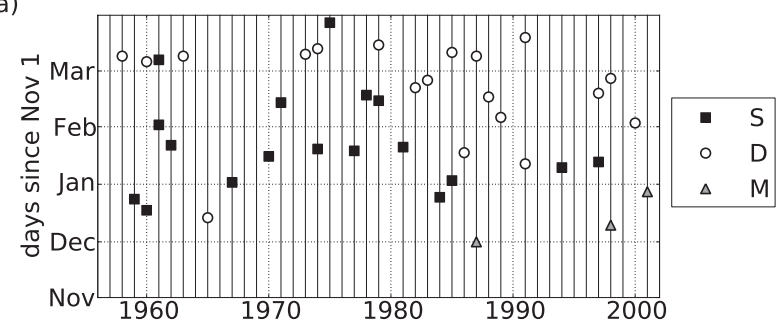

(b)

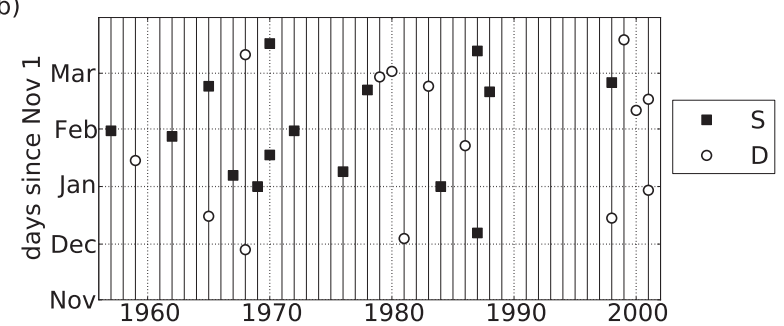

FIG. 3. Seasonal distribution of splitting (square), displacement (circle), and mixed (triangle) events. The abscissa denotes the year in which a given $\mathrm{NH}$ winter begins and the ordinate gives the intraseasonal timing of the event. Shown are (top) events defined in this study and (bottom) events defined in CP07.

in the vortex centroid to define displacements. If the vortex air mass becomes symmetrically disturbed about the pole, these diagnostics may well not define an event.

\section{Analysis}

Using our set of displacement and splitting events, the time-height evolution of the NAM over the winter period (October-March) is examined (Fig. 4). Anomalies during a vortex splitting event (bottom) seem to have a greater influence on the surface than during a displacement event (top). The signal during displacement events stops at the tropopause whereas it can descend to the surface during splitting events where it persists for $\sim 60$ days. The vertical evolution between the two types of event also varies, with splitting events occurring almost instantaneously throughout the depth of the stratosphere, suggesting an excitation of the barotropic mode and lending support to the idea of wave resonance (Esler and Scott 2005). The peak tropospheric signal occurs around 30 days following the event onset (we note that this result is not dominated by a few anomalous events) and suggests that if one has knowledge that a weak vortex event has begun, surface effects may be predictable on these time scales (Christiansen 2005). However, a positive NAM anomaly is observed in the stratosphere as a precursor to both displacement and splitting events (Fig. 4), and is strong enough that an elevated tropopause is observed (Ambaum and Hoskins 2002) (solid black line). Consequently, a further measure

a.

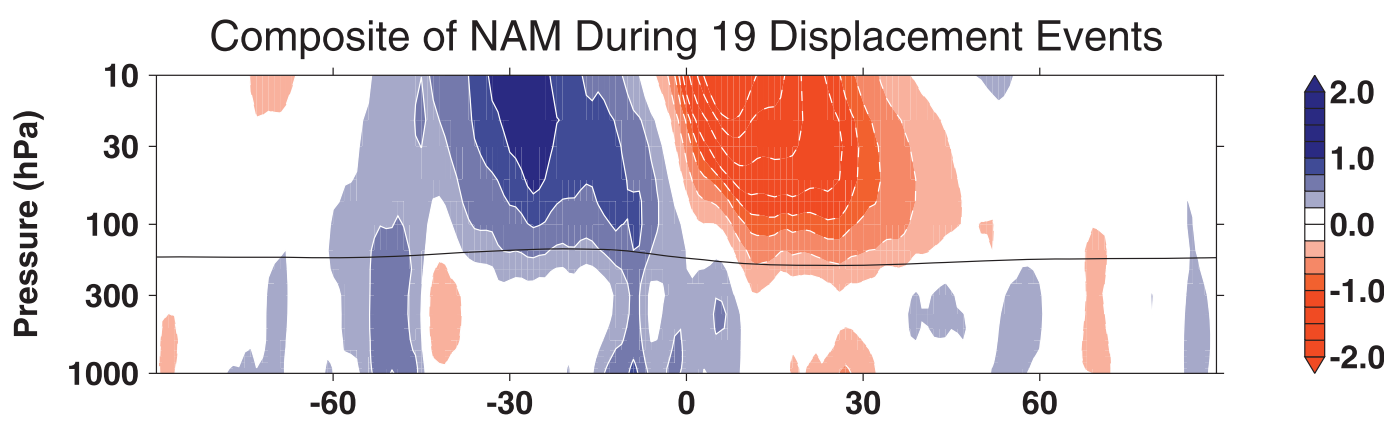

b.

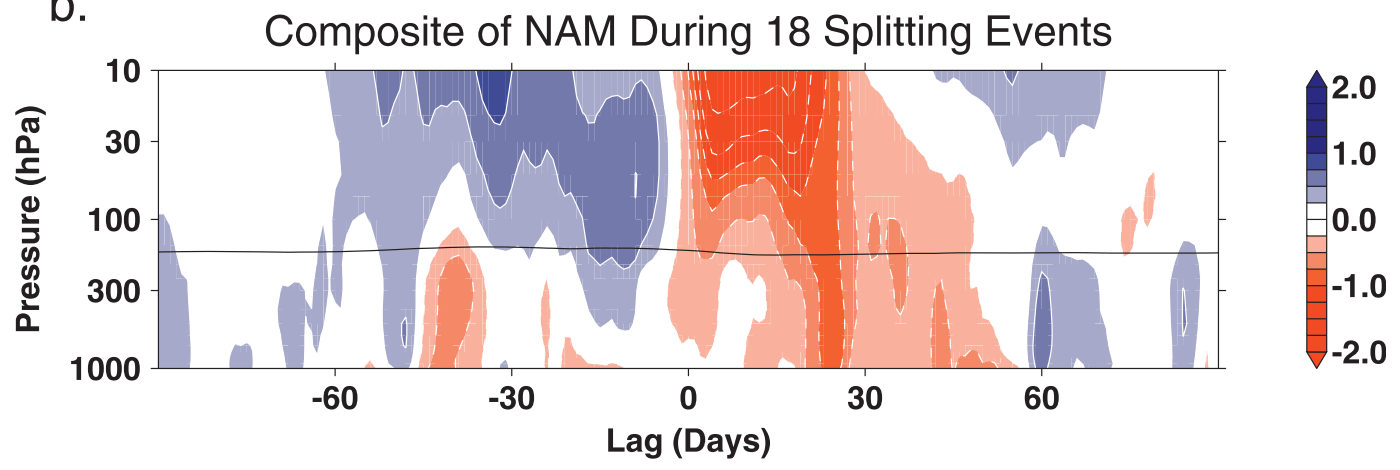

FIG. 4. Composites of the time-height evolution of the NAM during (a) 19 vortex displacement events and (b) 18 splitting events. The horizontal line is a composite of the thermal tropopause level for the two types of event. Lag 0 shows the onset of an event as measured at $10 \mathrm{hPa}$. Contour intervals are 0.25 and the region between -0.25 and 0.25 is unshaded. 
a. NAM Before Event

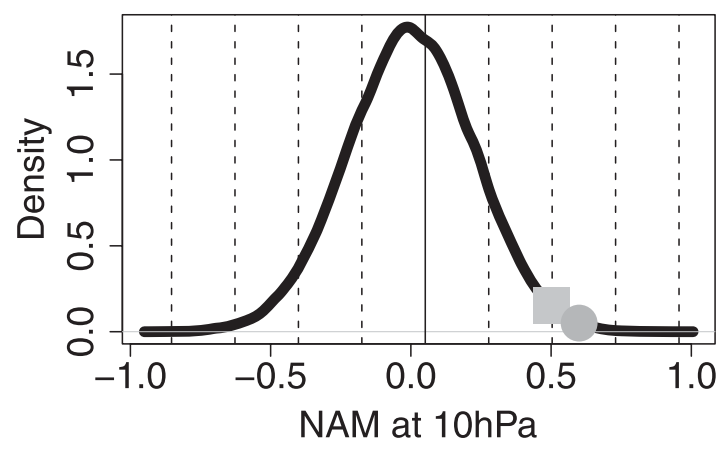

b. NAM After Event

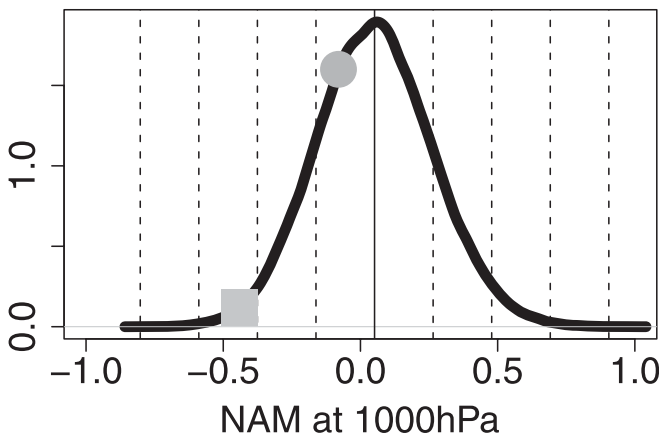

FIG. 5. (a) The PDF of the mean NAM at $10 \mathrm{hPa}$ during 18 randomly averaged 45 -day periods, resampled $10^{5}$ times. The square (circle) gives the NAM value for the period between -45 and 0 days before splitting (displacement) events. (b) As in (a), but for the NAM at $1000 \mathrm{hPa}$ and over the period between 15 and 60 days following an event. The vertical solid line shows the mean of the PDF. The vertical dashed lines show the std dev of the PDF (see section 2 for more details).

of predictability up to a month before the onset of these events may be apparent. To determine the significance of the positive stratospheric NAM precursors, and subsequently its use for potential predictability, we test how likely it is that events of this magnitude occur over random periods during the winter. This is assessed by randomly resampling the mean of the NAM over 45-day periods at $10 \mathrm{hPa}$ during winter (Fig. 5a, PDF) and then comparing with the same measure calculated during splits (squares) and displacements (circles). ${ }^{2} \mathrm{We}$ observe that during both displacements and splits, the positive NAM signal is over two standard deviations from the mean of randomly sampled events and is therefore statistically significant at the $95 \%$ level.

Perhaps more important is the surface NAM [Arctic Oscillation (AO)] signal from each type of event and this is assessed using the same resampling technique, although now the surface signal for the period 15-60 days following (as opposed to preceding) an event is studied (Fig. 5b). For splitting events (square) the AO has a mean value of -0.43 , and is greater than two standard deviations from the mean of the PDF. In contrast, the mean AO following displacement events (circle) is not significantly different from the mean of the PDF. This implies that surface variability associated with the $\mathrm{AO}$, such as an increased occurrence of high-latitude blocking and modulation of the midlatitude storms (Thompson and Wallace 2001), is far more likely following splitting events than displacements. This result is in agreement with Nakagawa and Yamazaki (2006),

\footnotetext{
2 This period was chosen to allow time for anomalies to propagate to the surface following an event onset. Changing the period decreases the magnitude of the signal, but crucially does not alter the significance.
}

who showed that events with enhanced upward flux of wavenumber- 2 scale planetary waves were more likely to propagate to the surface than those with a reduced upward flux (see also Yoden et al. 1999). However, it is noted that not all vortex splitting events are dominated by wave- 2 activity.

It could be argued, however, that it is not only the instantaneous NAM response that matters when considering the tropospheric impact from a weak vortex event, but also the tendency in the NAM at the surface. For instance, one can see a positive $\mathrm{AO}$ anomaly during the displacement onset (Fig. 4a) followed by a negative AO anomaly $\sim 30$ days following the event. Likewise for the splitting events, a weak negative AO anomaly is observed during the event onset that proceeds to become more strongly negative after $\sim 30$ days. In terms of the AO trend these events would seem quite similar. We

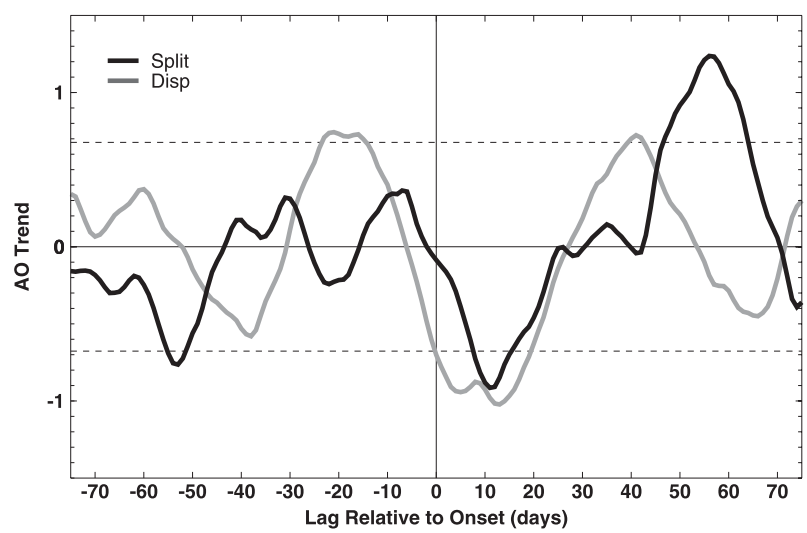

FIG. 6. Trend in the time series of the average AO for splits (black) and displacements (gray) \pm 15 days on either side of the lag day. Days are lagged relative to the event onset (day 0). Units are change in AO per month. Dashed lines show values of the AO trend which are significant at the $95 \%$ level using a Monte Carlo resampling test. 
Displacements
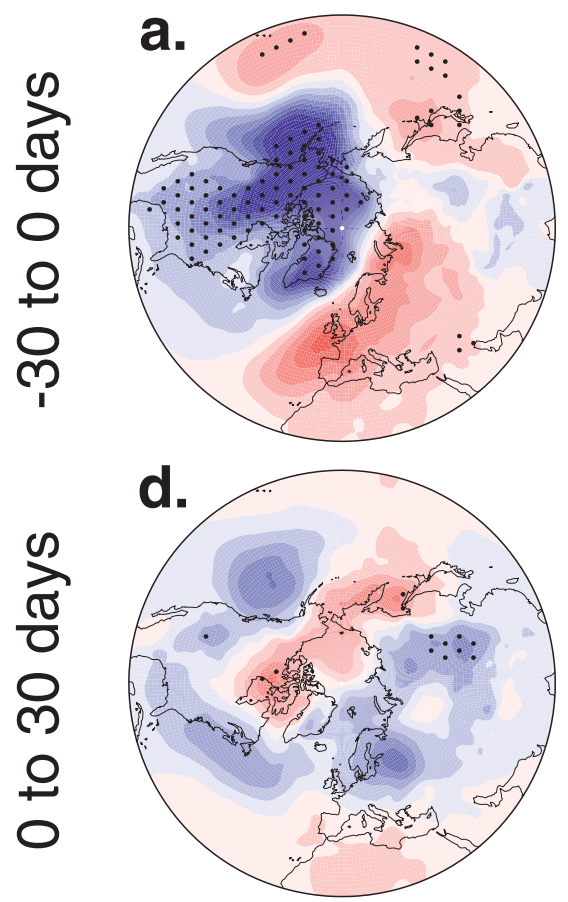

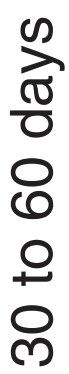
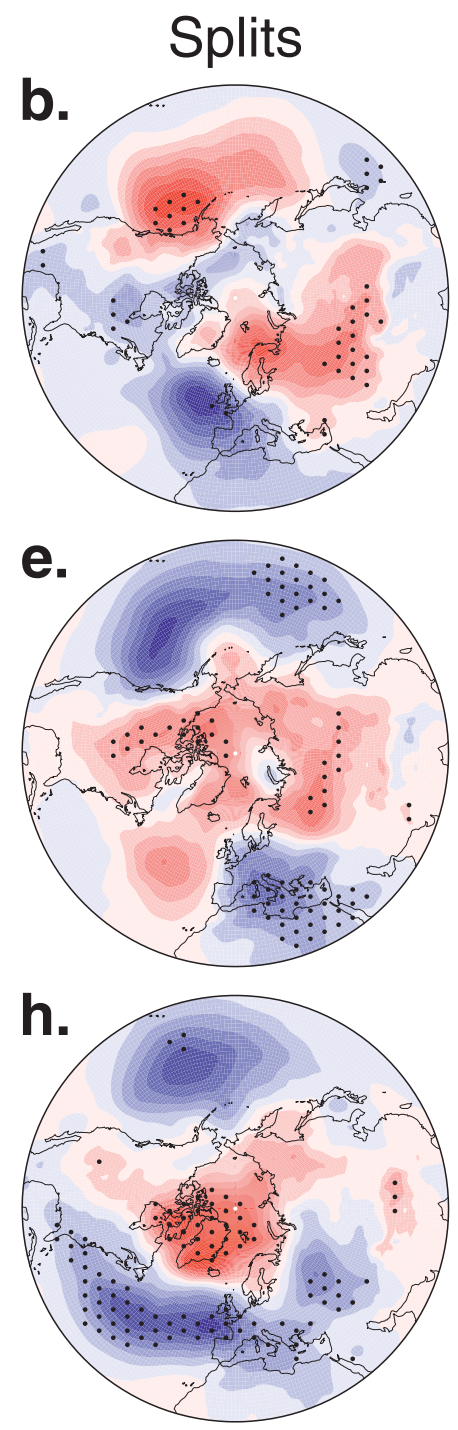

Difference (S-D)
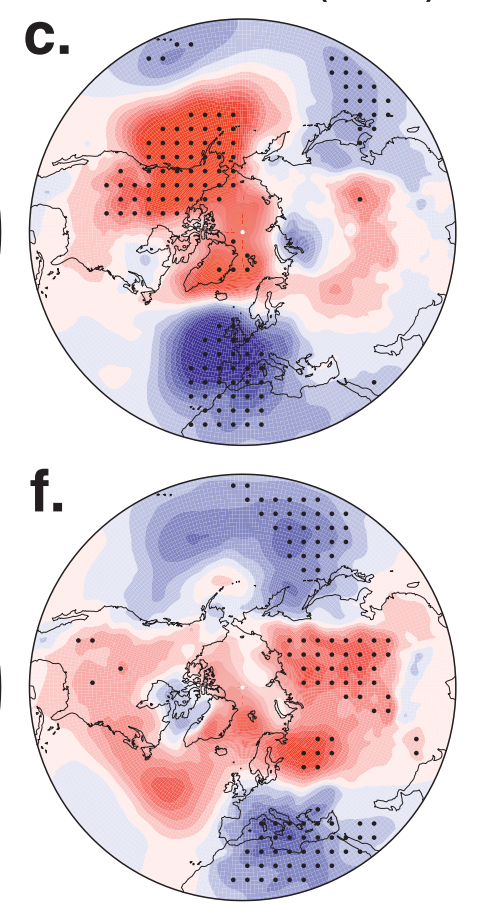

i.

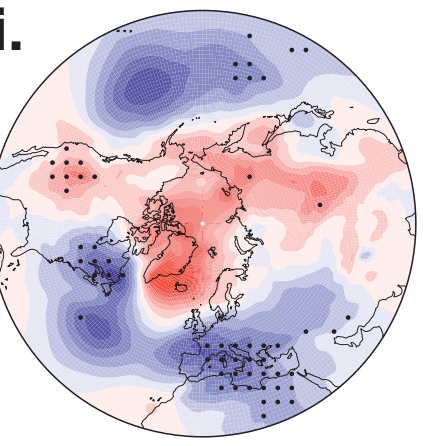

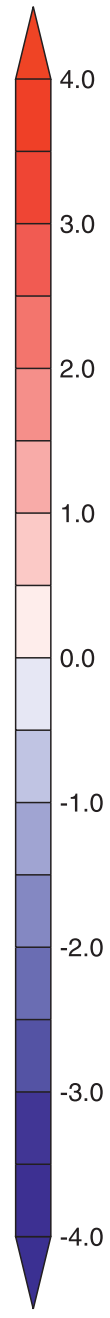

Anomaly $(\mathrm{hPa})$

FIG. 7. Composites of MSLP in the NH during vortex (left) displacement events and (middle) splitting events, and (right) the difference taken as split minus displacement. Shown are composites of (top) the precursor stage (lag $=$ from -30 to 0 days), (middle) the mature stage (lag $=$ from 0 to 30 days), and (bottom) the decay phase (lag = from 30 to 60 days). Red regions are positive and blue are negative. Stippled areas show statistical significance at the $95 \%$ level according to a Student's $t$ test.

therefore plot the trend in the time series of the average AO for splits and displacements (Fig. 6, gray and black lines respectively). ${ }^{3}$ The trends are calculated for \pm 15 days either side of each lagged day from the onset. For example, at lag $=0$ we are calculating the trend in the $\mathrm{AO}$ for the period of 15 days before the event onset to 15 days after the event onset. At lag $=1$ we do the same but for 14 days before the event onset to 16 days after, and so on. Here we observe that both splits and displacements

\footnotetext{
${ }^{3}$ The trend is calculated by applying a least squares linear fit to the time series.
}

do have a similar AO trend around 10 days following the event onset, and this is significant according to Monte Carlo resampling at the $95 \%$ significance level (given by the dashed lines). However, the AO values begin to recover earlier for displacements (at $\sim 40$ days after the onset) than for splits ( $\sim 55$ days), emphasizing the longer persistence time scales associated with splitting events.

To contrast the large-scale atmospheric dynamics between the two types of event and understand better the surface influences between them, we proceed to analyze the mean sea level pressure (MSLP) anomalies during three separate periods. We choose the 30 days prior to the onset (precursor stage), 30 days after the onset 
a. MSLP (Clim, DJF)

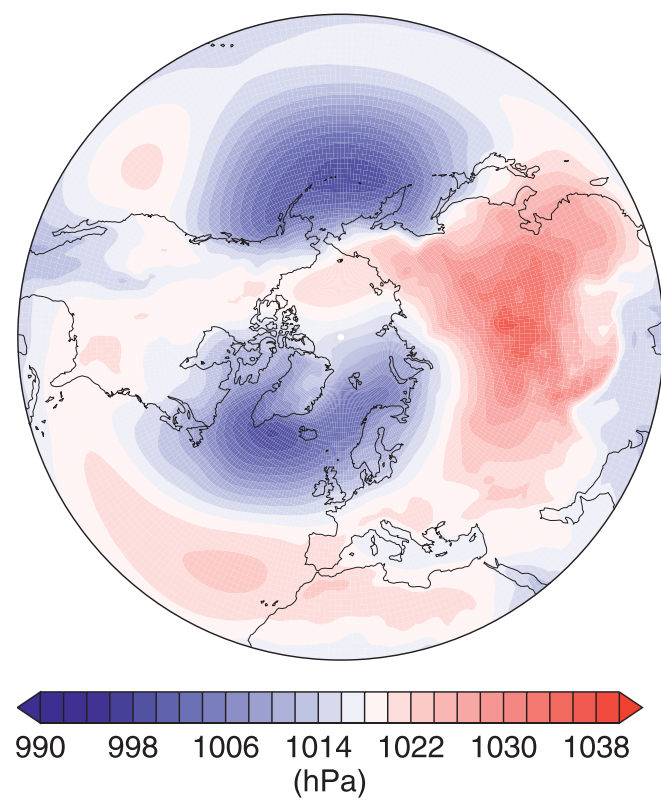

b. MSLP (SDev, DJF)

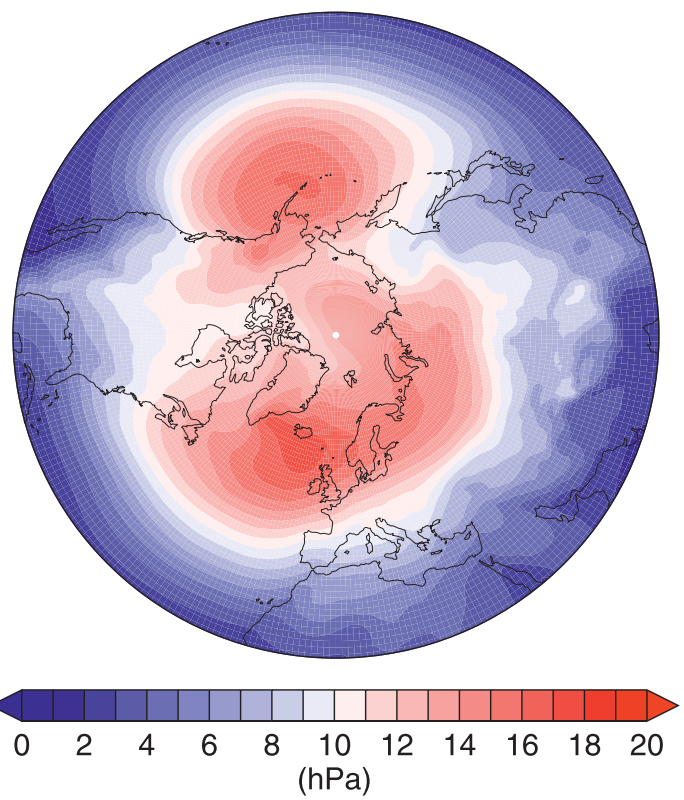

FIG. 8. Polar stereographic projections of the daily MSLP (a) climatology and (b) std dev over winters (DJF) from 1958 to 2002.

(mature stage), and 30 days following the mature stage (decay stage) (Kolstad and Charlton-Perez 2010; Limpasuvan et al. 2004) (Fig. 7). Note that the December-February (DJF) mean and variance fields in MSLP (Fig. 8) do not vary greatly between December and February, and therefore the DJF composites can be used with confidence to interpret winter anomalies. The strongest MSLP anomaly is observed as a precursor to displacement events (Fig. 7a) and shows a wave-1 structure that projects well onto the stationary wave pattern (Garfinkel and Hartmann 2008), allowing for enhanced propagation of wave- 1 anomalies into the stratosphere. During the mature and decay phases following the displacement (Figs. 7d,g), very little surface signal is observed, consistent with the previous analysis.

A precursor signal is also observed before the splitting events (Fig. 7b), and while this does not project well onto the NAM, it does show wave-2 features and is consistent with previous studies (Garfinkel et al. 2010). Over the two periods following the splitting event (Figs. $7 e, h)$ an equatorward shift and a deepening is observed in both the Aleutian and Icelandic lows (for reference to the climatology, see Fig. 8), a pattern that is reminiscent of a negative NAM. Consequently, it is likely that following splitting events storm tracks would shift equatorward and mobile cyclones would be enhanced at lower latitudes (Thompson and Wallace 2001).

It is also useful to consider the difference in the surface response for the two types of event relative to each other, rather than relative to the climatology. Figure 7 (right) therefore plots the split minus displacement difference. Statistically the largest differences are observed in the precursor stage, implying that MSLP patterns are distinct preceding splits and displacements. However, for all 60 days following an event anomalously low pressures are observed over the northern Africa and western Europe regions, suggesting usefulness for a priori knowledge of an event type in seasonal forecasting over this region.

It should be noted here that CP07 did a similar analysis using their definitions of splits and displacements and found that a negative NAM response was present in both the splitting and displacement cases, albeit weaker than the negative NAM response reported in this study for splitting events. No doubt the differences here arise in how we characterize events; however, more strong negative NAM events (or likewise fewer weak NAM events) make up the split composite in our study than do either of the composites in CP07.

To expand on this we consider regional projections of the surface temperature that are important for seasonalscale climate forecasts (Fig. 9). Consistent with the strong cyclonic flow of air around the anomalous low over North America, observed in the MSLP precursor to displacement events, temperature anomalies exceed $3 \mathrm{~K}$ over mainland North America (Fig. 9a). The subsequent mature and decay phases show little significance except for highmagnitude cold anomalies of $\sim-1.5 \mathrm{~K}$ in the mid to high 
Displacements
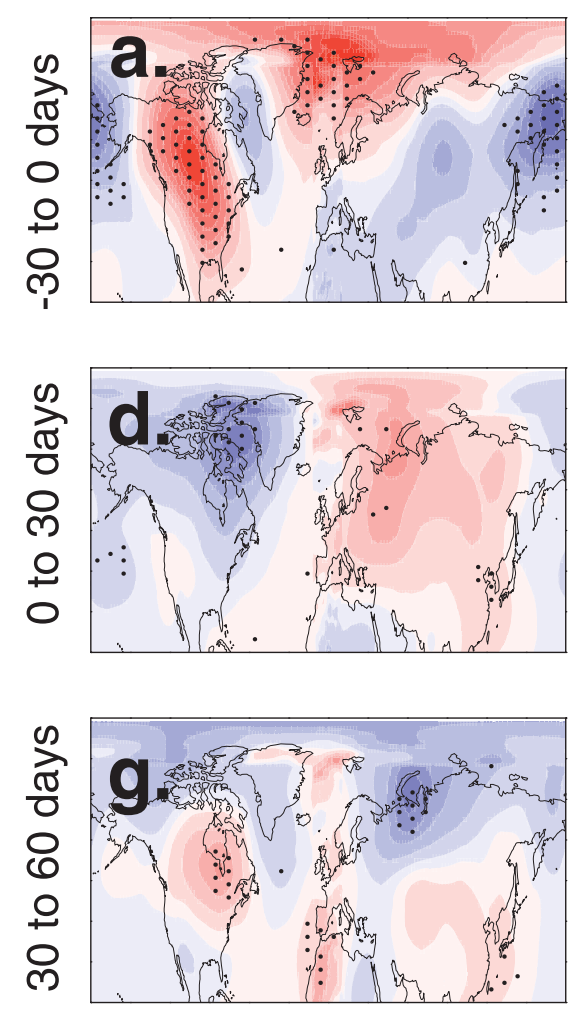

Splits
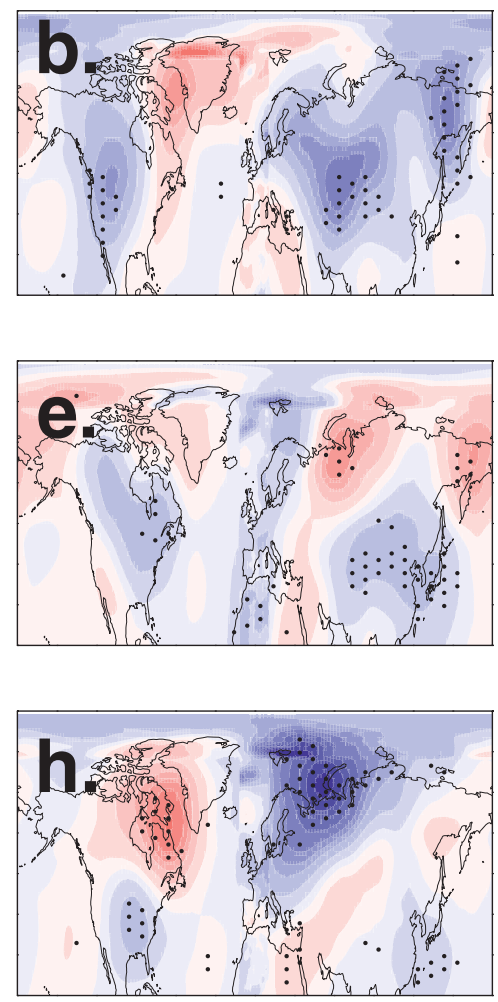

\section{Difference (S-D)}
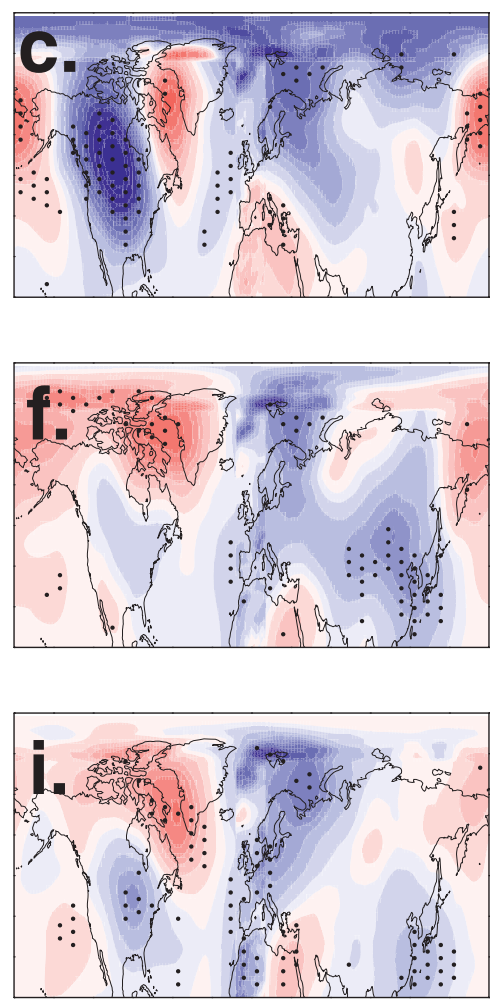

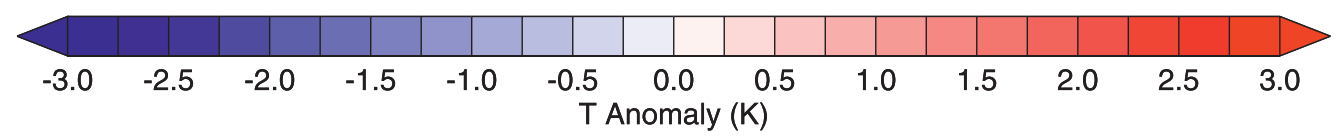

FIG. 9. Surface temperature anomalies in the NH during vortex (left) displacement events and (middle) splitting events, and (right) the difference taken as split minus displacement, for (top) the from -30 to 0 day period before the event, (middle) the $0-30$-day period after the event, and (bottom) the 30-60-day period after the event. The fields have been smoothed using a 10-point smoothing filter to emphasize larger scales. Statistically significant areas at the $95 \%$ level according to a Student's $t$ test are stippled.

latitudes over the Americas (Fig. 9d). Previous studies have noted the occurrence of "cold-air outbreaks" in this region (Thompson et al. 2002; Kolstad and CharltonPerez 2010); however, this analysis shows that such outbreaks often occur following displacement events rather than splitting events. Because of the strong precursors associated with these events, a measure of predictability can be inferred.

In comparison, during the precursor stage of splitting events (Fig. 9b) cold anomalies are observed over North America and throughout Eurasia, whereas warmer anomalies are observed over Greenland. The mature stage shows a different response to that of displacement events and indicates a $-1-\mathrm{K}$ anomaly over southern Eurasia. However, the largest impact from either type of weak vortex event is evident during the decay period of a splitting event (Fig. 9h), during which a strong temperature dipole is observed with warm anomalies of up to $1.5 \mathrm{~K}$ over eastern North America, and cold anomalies of up to $-3 \mathrm{~K}$ over northern Eurasia. These strong negative anomalies are twice as large as the cold-air outbreaks noted over North America during displacement events and are unique to splitting events. It is noted, however, that the surface temperature patterns are similar for both types of event during the decay phase, and it is the intensity of the signal that is most dissimilar.

As before, we also consider the difference (split minus displacement) in surface temperatures (Figs. 9c,f,i). Consistent with the MSLP analysis, a strong difference is observed in the precursor stage, as well as a cold bias following a split compared to a displacement over North Africa and western Europe for all 60 days after the event, highlighting the influence of the stratospheric state on this region.

With a change in temperatures over lands and ocean an inevitable change in the land-sea contrast is observed, 


\section{strong NAM}

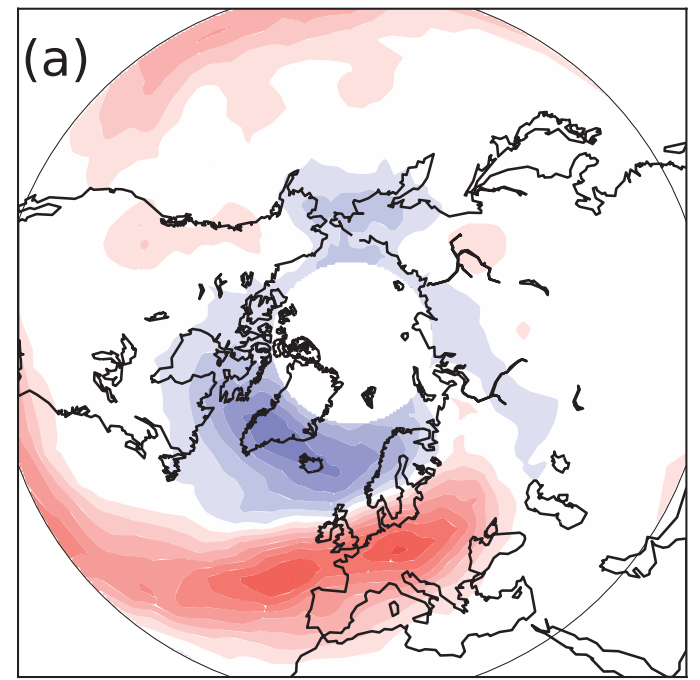

weak NAM
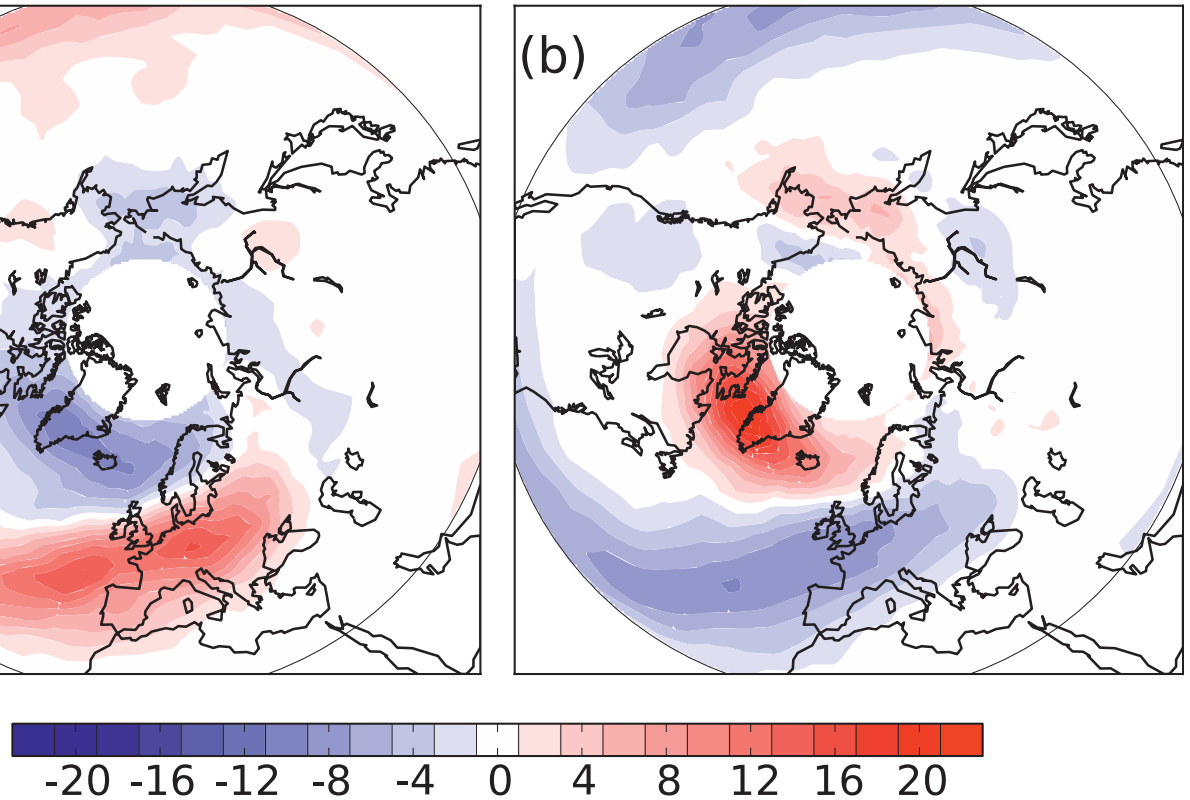

FIG. 10. Composites of deseasonalized blocking frequency at $Z_{500}$ in the $\mathrm{NH}$ for (left) strong positive AO events and (right) strong negative AO events. Units are blocking frequency per day.

and hence Rossby wave generation can be modified. This could potentially lead to a change in tropospheric blocking events (Andrews et al. 1987), which are known to result in persistently anomalous weather conditions. To tie in the blocking with the NAM response we observed in Fig. 4, we first composite blocking activity for strong $\mathrm{AO}(\mathrm{AO}>1.6)$ and weak $\mathrm{AO}(\mathrm{AO}<-1.6)$ events (Fig. 10; for a description of how we calculated the blocking index, see section 2c). Here we see that in both cases the largest response is over the Atlantic and European regions. Specifically, for the weak AO events (which are important for our analysis) increased blocking activity is observed over the North Atlantic, and decreased activity is observed in a band spanning from the mid-Atlantic to western Europe.

Considering the optimal periods where splits and displacements interact with the surface (i.e., from Fig. 4), we composite the instantaneous blocking for displacements, splits, and the difference (split minus displaced) in Fig. 11.

During the period before a displacement event we observe an increased occurrence of Eurasian blocking and decreased occurrence of blocking over the Atlantic and Pacific basins. This is in agreement with Woollings et al. (2010), who show a similar spatial pattern to that of a positive AO (i.e., Fig. 10b), demonstrating good agreement with the positive NAM anomaly observed to descend from the stratosphere as a precursor to displacements. Note that if a 5-day persistence criterion is imposed on the blocking definition, the blue region becomes less significant. Interestingly, the blocking activity following a displacement shows an increase over Canada that may well be linked to the cold-air outbreaks in this region (note that the blocking index that we are using shows Canada to be an area of low blocking activity).

While at the $95 \%$ level $^{4}$ the significance of blocking activity is low for the period before splits (Fig. 11b), at the $90 \%$ level a significant increase is observed over the North Atlantic and northern Eurasia (not shown), hinting at a wave-2 type pattern. The period following a split does, however, show more of a signal. The spatial pattern suggests a strong negative AO (Fig. 10a) and agrees well with the downward propagation of a weak NAM signal observed during a vortex splitting event. In particular, large decreases in blocking activity can be seen over the Atlantic and European sectors and the blocking pattern over northern Eurasia is consistent with the large cold anomaly observed in Fig. 9. The split minus displacement difference (Fig. 11f) in this region is also large and, when taken in conjunction with the surface temperature and MSLP analyses, it is clear that this

\footnotetext{
${ }^{4}$ We choose to use a Monte Carlo method of significance testing (see section 2) because the underlying distribution of blocking activity is not assumed to be Gaussian.
} 
Displacements
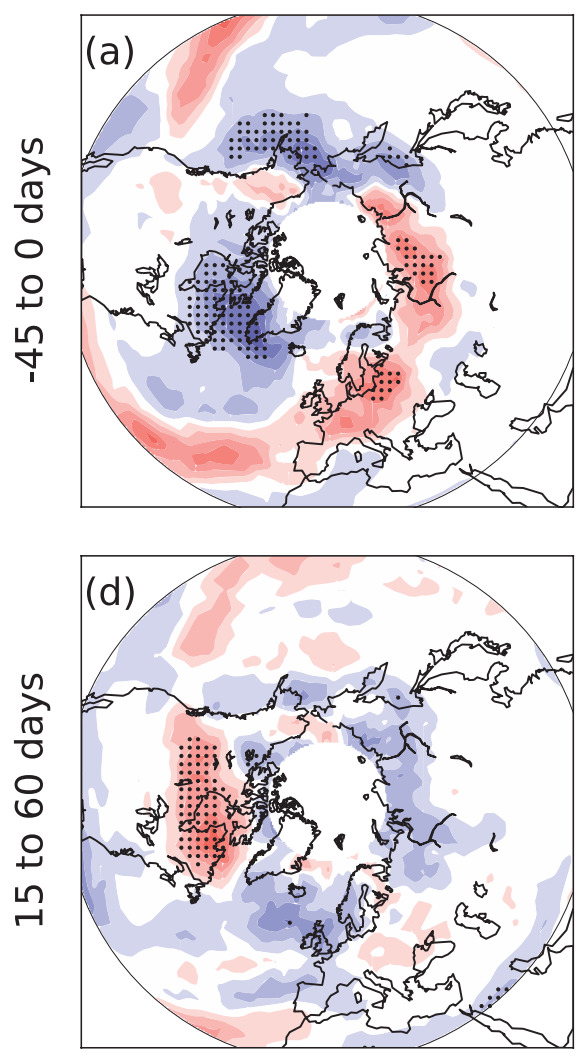

Splits
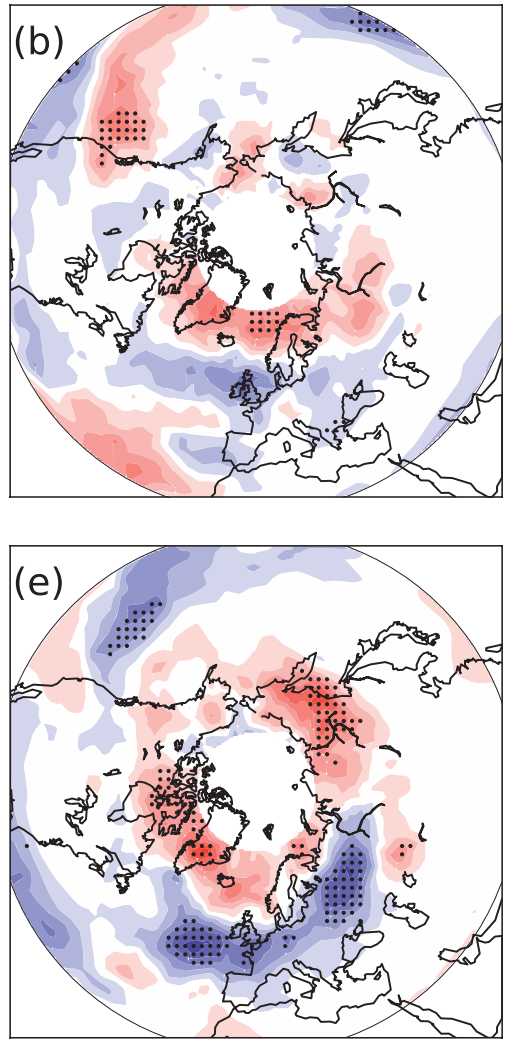

Difference (S-D)
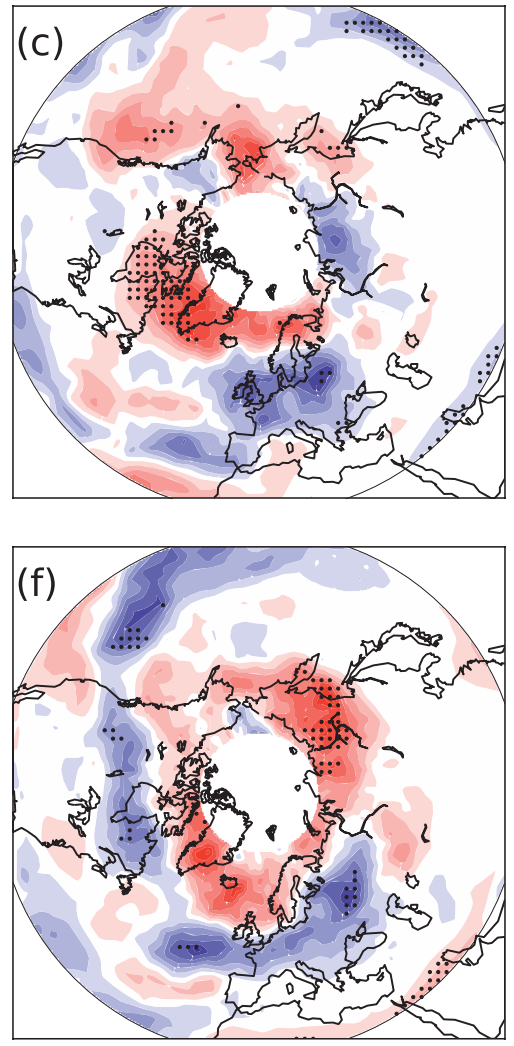

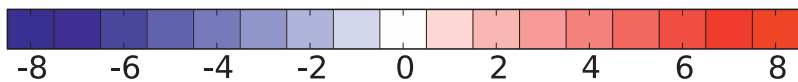

FIG. 11. Composites of deseaonalized blocking frequency at $Z_{500}$ in the NH for vortex (left) displacement and (middle) splitting events, and (right) the difference taken as split minus displacement. Shown are composites (top) before an event (lag $=$ from -45 to 0 days) and (bottom) after an event (lag = from 15 to 60 days). Units are blocking frequency in events per day, expressed as the percentage of blocking days. Stippled areas show statistical significance at the 95\% level using a Monte Carlo method for the composites, and a Student's $t$ test for the differences.

is a region of importance when considering the different influences of weak vortex events on surface climate.

\section{Summary}

In this paper we have developed a novel method of defining polar vortex splits and displacement. This method has been contrasted against that of Charlton and Polvani (2007) to reveal advantages and disadvantages of using both, and most importantly we have shown that one must treat vortex splitting and displacement events individually if a true representation of the subsequent surface influence is to be achieved. To do this the most up-to-date measures of vortex variability and tropospheric blocking have been employed and yield the following conclusions:

\section{a. Vortex displacements}

- Preceding these events are often anomalously low pressure systems over North America and high pressure systems over western Europe and the Pacific. Associated with this are warm temperature anomalies over Northern America and an increase in blocking over northern Eurasia.

- While the stratospheric NAM anomaly is large for these events, with a potential for predictability up to a month before hand, the anomaly is not seen to descend through the troposphere. At the surface the AO trend is similar around the onset date for both splits and displacements, although the AO anomaly persists for $\sim 15$ days less during displacements.

- The largest surface impact from displacement is observed over the month following an event and shows anomalously cold temperatures of magnitude $-1.5 \mathrm{~K}$ over North America, a feature that is not observed for the splitting case. Associated with this, increased blocking activity is observed over Canada. 


\section{b. Vortex splits}

- Preceding splitting events are anomalously low temperatures over Eurasia, with a wave-2-like pattern observed in MSLP.

- The midstratospheric NAM signal following splitting events is weaker than that which follows displacements events, but importantly anomalies can descend from the midstratosphere to the surface, unlike displacement events. The evolution of the anomalies are also far more barotropic than during displacement events.

- For 60 days following a splitting event a coherent negative AO anomaly is observed. Consistent with this, high-latitude blocking in both the Atlantic and Pacific basins increases while blocking in the midAtlantic, Europe, and western Eurasia decreases. Ultimately the largest effect from these events is observed over northern Eurasia with low temperature anomalies of up to $-3 \mathrm{~K}$.

Recently many studies have alluded to the stratospheric involvement in extended range forecasting (e.g., Christiansen 2005; Fletcher et al. 2007; Hardiman et al. 2011). The implications of these results for monthlyscale climate forecasts in the high northern latitudes are great and the different surface response to displaced and split vortex events demonstrates the necessity for forecasting systems, and climate models, to correctly simulate the evolution and frequency of these two types of vortex disturbances. On a fundamental level this will involve models including a fully resolved stratosphere with an excellent representation of how the structure and evolution of the Arctic polar vortex varies throughout winter, so that the distinct influence from splitting and displacement events can be appropriately captured.

Acknowledgments. We are grateful for the insightful comments from Chaim Garfinkel and the two anonymous reviewers. We would also like to thank Brian Hoskins and Lorenzo Polvani for discussions regarding this study. DMM and JA are supported by a grant from the UK Natural Environmental Research Council (NERC) and LJG is funded by the NERC National Centre for Atmospheric Science (NCAS).

\section{REFERENCES}

Ambaum, M., and B. Hoskins, 2002: The NAO tropospherestratosphere connection. J. Climate, 15, 1969-1978.

Andrews, D., J. Holton, and C. Leovy, 1987: Middle Atmosphere Dynamics. Academic Press, 489 pp.

Baldwin, M., 2001: Annular modes in global daily surface pressure. Geophys. Res. Lett., 28, 4115-4118.
— , and T. Dunkerton, 2001: Stratospheric harbingers of anomalous weather regimes. Science, 294, 581-584.

_ , and D. Thompson, 2009: A critical comparison of stratospheretroposphere coupling indices. Quart. J. Roy. Meteor. Soc., 135, 1661-1672.

Bell, C., L. Gray, A. Charlton-Perez, M. Joshi, and A. Scaife, 2009: Stratospheric communication of El Niño teleconnections to European winter. J. Climate, 22, 4083-4096.

Charlton, A., and L. Polvani, 2007: A new look at stratospheric sudden warmings. Part I: Climatology and modeling benchmarks. J. Climate, 20, 449-469.

Christiansen, B., 2001: Downward propagation of zonal mean zonal wind anomalies from the stratosphere to the troposphereModel and reanalysis. J. Geophys. Res., 106, 27 307-27 322.

- 2005: Downward propagation and statistical forecast of the near-surface weather. J. Geophys. Res., 110, D14104, doi:10.1029/2004JD005431.

Esler, J., and R. Scott, 2005: Excitation of transient Rossby waves on the stratospheric polar vortex and the barotropic sudden warming. J. Atmos. Sci., 62, 3661-3682.

Fletcher, C., P. Kushner, and J. Cohen, 2007: Stratospheric control of the extratropical circulation response to surface forcing. Geophys. Res. Lett., 34, L21802, doi:10.1029/2007GL031626.

Garfinkel, C., and D. Hartmann, 2008: Different ENSO teleconnections and their effects on the stratospheric polar vortex. J. Geophys. Res., 113, D18114, doi:10.1029/2008JD009920.

,-- , and F. Sassi, 2010: Tropospheric precursors of anomalous Northern Hemisphere stratospheric polar vortices. J. Climate, 23, 3282-3299.

Hannachi, A., D. Mitchell, L. Gray, and A. Charlton-Perez, 2011: On the use of geometric moments to examine the continuum of sudden stratospheric warmings. J. Atmos. Sci., 68, 657-674.

Hardiman, S. C., and Coauthors, 2011: Improved predictability of the troposphere using stratospheric final warmings. J. Geophys. Res., 116, D18113, doi:10.1029/2011JD015914.

Hoskins, B., M. McIntyre, and A. Robertson, 1985: On the use and significance of isentropic potential vorticity maps. Quart. J. Roy. Meteor. Soc., 111, 877-946.

Kolstad, E., and A. Charlton-Perez, 2010: Observed and simulated precursors of stratospheric polar vortex anomalies in the Northern Hemisphere. Climate Dyn., 37, 1443-1456.

Limpasuvan, V., D. Thompson, and D. Hartmann, 2004: The life cycle of the Northern Hemisphere sudden stratospheric warmings. J. Climate, 17, 2584-2596.

Matthewman, N., J. Esler, A. Charlton-Perez, and L. Polvani, 2009: A new look at stratospheric sudden warmings. Part III: Polar vortex evolution and vertical structure. J. Climate, 22, 1566-1585.

Mitchell, D., A. Charlton-Perez, and L. Gray, 2011a: Characterizing the variability and extremes of the stratospheric polar vortices using 2D moment analysis. J. Atmos. Sci., 68, 1194-1213.

, L. Gray, and A. Charlton-Perez, 2011b: The structure and evolution of the stratospheric vortex in response to natural forcings. J. Geophys. Res., 116, D15110, doi:10.1029/2011JD015788.

— S. Osprey, L. Gray, N. Butchart, S. Hardiman, A. CharltonPerez, and P. Watson, 2012a: The effect of climate change on the variability of the Northern Hemisphere stratospheric polar vortex. J. Atmos. Sci., 69, 2608-2618.

, and Coauthors, 2012b: The nature of arctic polar vortices in chemistry-climate models. Quart. J. Roy. Meteor. Soc., 138, 1681-1691.

Nakagawa, K., and K. Yamazaki, 2006: What kind of stratospheric sudden warming propagates to the troposphere? Geophys. Res. Lett., 33, L04801, doi:10.1029/2005GL024784. 
Nash, E., P. Newman, J. Rosenfield, and M. Schoeberl, 1996: An objective determination of the polar vortex using Ertel potential vorticity. J. Geophys. Res., 101, 9471-9478.

Perlwitz, J., and N. Harnik, 2003: Observational evidence of a stratospheric influence on the troposphere by planetary wave reflection. J. Climate, 16, 3011-3026.

Scherrer, S., M. Croci-Maspoli, C. Schwierz, and C. Appenzeller, 2006: Two-dimensional indices of atmospheric blocking and their statistical relationship with winter climate patterns in the Euro-Atlantic region. Int. J. Climatol., 26, 233-249.

Thompson, D., and J. Wallace, 1998: The Arctic Oscillation signature in the wintertime geopotential height and temperature fields. Geophys. Res. Lett., 25, 1297-1300.

_, and —, 2001: Regional climate impacts of the Northern Hemisphere annular mode. Science, 293, 85-89.

__, M. Baldwin, and J. Wallace, 2002: Stratospheric connections to Northern Hemisphere wintertime weather: Implications for prediction. J. Climate, 15, 1421-1428.

Tibaldi, S., and F. Molteni, 1990: On the operational predictability of blocking. Tellus, 42A, 343-365.
Waugh, D., 1997: Elliptical diagnostics of stratospheric polar vortices. Quart. J. Roy. Meteor. Soc., 123, 1725-1748.

_ vortices using elliptical diagnostics. J. Atmos. Sci., 56, 1594-1613.

Wilcox, L., B. Hoskins, and K. Shine, 2012: A global blended tropopause based on ERA data. Part I: Climatology. Quart. J. Roy. Meteor. Soc., 138, 561-575.

Wilks, D., 1995: Statistical Methods in the Atmospheric Sciences: An Introduction. Academic Press, $467 \mathrm{pp}$.

Wittman, M., A. Charlton, and L. Polvani, 2007: The effect of lower stratospheric shear on baroclinic instability. J. Atmos. Sci., 64, 479-496.

Woollings, T., A. Charlton-Perez, S. Ineson, A. Marshall, and G. Masato, 2010: Associations between stratospheric variability and tropospheric blocking. J. Geophys. Res., 115, D06108, doi:10.1029/2009JD012742.

Yoden, S., T. Yamaga, S. Pawson, and U. Langematz, 1999: A composite analysis of the stratospheric sudden warmings simulated in a perpetual January integration of the Berlin TSM GCM. J. Meteor. Soc. Japan, 77, 431-445. 